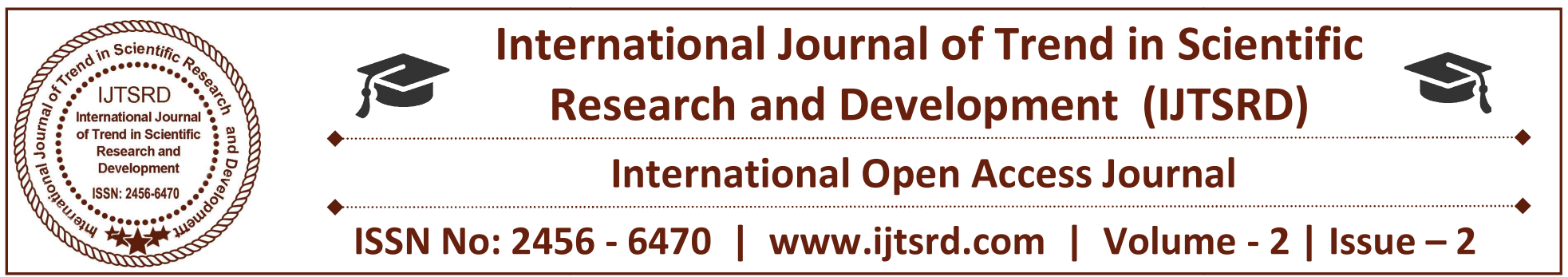

\title{
Synthesis of Thin Film Ternary Chalcogenide Glasses and Study of its Optical Properties
}

\author{
Vivek Kumar Dwivedi \\ Associate Professor, Department of Physics, \\ Brahmanand College, Kanpur, India
}

\section{ABSTRACT}

In the present work, a systematic investigation of Tellurium based ternary chalcogenide semiconducting materials $\mathrm{Se}-\mathrm{Te}-\mathrm{Ga}$ has been undertaken. The system $\mathrm{Se}_{70-\mathrm{x}} \mathrm{Te}_{30} \mathrm{Ga}_{\mathrm{x}}(0<\mathrm{x}<10)$ has been studied in detail with emphasis on the effect of Gallium in SeTe binary components. Bulk glasses of Se-Te-Ga systems and thin films are prepared by the conventional melt quenching technique and by thermal evaporation technique, respectively. The effect of compositional variation on some optical constant has been observed and discussed in the present investigation.

\section{INTRODUCTION}

Chalcogenide glass is a glass containing one or more chalcogens containing Se, Te and S. Such glasses are covalently bonded materials. The classical chalcogenide glasses (mainly sulfur-based ones such as As-S or Ge-S) are strong glass-formers and possess glasses within large concentration regions. Glassforming abilities decrease with increasing molar weight of constituent elements; i.e., $\mathrm{S}>\mathrm{Se}>\mathrm{Te}$.

Most stable binary chalcogenide glasses are compounds of a chalcogen and a group 14 or 15 element and may be formed in a wide range of atomic ratios. Ternary glasses [1] are also known. Not all chalcogenide compositions exist in glassy form, though it is possible to find materials with which these non-glass-forming compositions can be alloyed in order to form a glass. An example of this is gallium sulphide-based glasses. In the last few years owing to their interesting properties and technological applications these materials are used in optical and photonic devices. They have good electro-optic, thermo-optic, magneto-optic, acousto-optic properties, high refractive index and I $R$ transparency. Chalcogenide glasses material heat to melt is the form of a liquid and at some instant freeze the position of every atom by quenching. Even in this freezed position they retain short range order and the position of the nearest neighbour remains nearly the same. These glasses are useful in the preparation of passive devices like lenses, windows, fibers etc. [2-4], active devices like laser fiber amplifiers [5] and non-linear components [6-8]. The present work has been carried out in order to investigate some optical properties of $\mathrm{Se}_{70-\mathrm{x}} \mathrm{Te}_{30} \mathrm{Ga}_{\mathrm{x}}(\mathrm{x}=0,0.5,5,10)$ system. The effect of incorporation of Gallium in Se-Te alloy can change the structural and optical properties of the system.

\section{EXPERIMENTAL}

Extra pure materials were weighed according to their atomic percentage and sealed in $6 \mathrm{~cm}$ long quartz ampoules with diameter $6 \mathrm{~mm}$ in the vacuum of $10^{-5}$ torr. The sealed ampoules were kept in a furnace at $700^{\circ} \mathrm{C}$ and were held at the same temperature for about 10 hours. During heating, all the ampoules were constantly rocked for better homogenization of the alloys. This was achieved with the help of a ceramic rod to which all the ampoules were tucked in the furnace. Thereafter, the obtained melts were cooled rapidly quenched into the ice cold water. The quenched samples were taken out by breaking the ampoules. The amorphous nature of the glassy alloys was identified by X - Ray diffraction. Thin films of 
International Journal of Trend in Scientific Research and Development (IJTSRD) ISSN: 2456-6470

glassy alloys of thickness $(\sim 300 \mathrm{~nm})$ were prepared by thermal evaporation technique in which substrate was kept at room temperature at a base pressure of $10^{-}$ ${ }^{4}$ torr using the molybdenum boat, the film was kept inside the deposition chamber for 24 hours to achieve the stable equilibrium [9]. The thickness of the film was measured by a single crystal thickness monitor.

\section{RESULTS AND DISCUSSION}

The value of optical absorption coefficient $(\alpha)$ as a function of incident photon (hv) for deposited thin films of Se-Te-Ga at room temperature is given in table 1.The absorption coefficient $(\alpha)$ is obtained using the relation

\section{Absorption Coefficient Density(OD)/Thickness(t) \\ $(\alpha) \quad=$ Optical}

Table 1 depicts that the value of absorption coefficient $(\alpha)$ increases linearly with the increase in photo energy of $\mathrm{Se}_{70-\mathrm{x}} \mathrm{Te}_{30} \mathrm{Ga}_{\mathrm{x}}$.Absorption of light [10] by amorphous solids depends on the energies of the incident photon and on the optical band gap of the material. Thus behavior may be represented by the equation given $\alpha \mathrm{h} v=\mathrm{B}(\mathrm{h} v-\mathrm{Eg})$ as given in literature[11], where $\mathrm{B}$ is a constant which depends on the transition probability, hv is energy of incident photon, Eg is optical band gap of the material, $r$ is an index which depends on the nature of transition [12] where $r=1 / 2$ and $r=2$ for allowed direct transition and indirect transition, respectively.

\section{Table 1: Variation of Absorption coefficient $(\alpha)$ with photon energy in a Se-Te-Ga thin films at room temperature.}

\begin{tabular}{|c|c|c|c|c|c|}
\hline \multirow[t]{2}{*}{ S. No. } & \multirow{2}{*}{$\begin{array}{l}\text { Photon } \\
\text { Energy } \\
\text { E (eV) }\end{array}$} & \multicolumn{4}{|c|}{ Absorption coeffifient $(\alpha)$ in $\mathrm{Cm}^{4}$} \\
\hline & & $\mathrm{Se}_{70} \mathrm{Te}_{30} \mathrm{Ga}_{0}$ & $\mathrm{Se}_{69.5} \mathrm{Te}_{30} \mathrm{Ga}_{0.5}$ & $\mathrm{Se}_{65} \mathrm{Te}_{30} \mathrm{Ga}_{5}$ & $\mathrm{Se}_{60} \mathrm{Te}_{30} \mathrm{Ga}_{10}$ \\
\hline 1. & 1.378 & 16555.656 & 8777.778 & $-2+3$ & 3988.889 \\
\hline 2. & 1.459 & 16555.656 & 8877.778 al J $\mathrm{C}$ & 3988.989 & 3988.889 \\
\hline 3. & 1.549 & 15000.00 & 7222.222 & 4766.767 & 4766.667 \\
\hline 4. & 1.907 & 23555.656 & 7222.222 & 18888.989 & 24333.333 \\
\hline 5. & 2.066 & 39888.989 & $16555.556 \mathrm{~h} a$ & 29122.322 & 39888.889 \\
\hline 6. & 2.254 & 63222.232 & 30555.556 & 50877.878 & 57800.000 \\
\hline 7. & 2.479 & 80333.433 & 43000.000 trte & 74788.889 & 71000.000 \\
\hline 8. & 2.754 & 111111.231 & 57000.000 & 111111.111 & 111111.111 \\
\hline 9. & 3.541 & 122777.878 & 89666.667 & 173333.333 & 147111.111 \\
\hline 10. & 4.131 & 227777.878 & 227777.778 & 266666.667 & 266666.667 \\
\hline
\end{tabular}

The present system obeys the rule of indirect transition and the relation between optical gap, optical coefficient $(\alpha)$ and the energy $h v$ of the incident photon is given by $(\alpha h v)^{1 / 2}=\mathrm{A}(\mathrm{h} v-\mathrm{Eg})$ where $\alpha$ obeys - Urbach relation [13] $\alpha=\exp \left[\mathrm{A}\left(\mathrm{h} v-\mathrm{h} v_{0}\right)\right] / \mathrm{kT}$ where $\mathrm{A}$ is a constant of the order of unity, $v_{0}$ is the constant corresponding to the lowest excitonic frequency.

The variation of $(\alpha h v)^{1 / 2}$ with photon energy hv for Se-Te-Ga films is given in table 3. The calculated values of $\mathrm{Eg}$ are given in table 2. It is evident from the table that the value of optical band (Eg) increases from 1.25 to 1.33 with increasing Ga content. The increase in the Eg with increasing Ga may be due to increase in grain size, the reduction in the disorder and decrease in density of defect states.

Table 2: Optical parameter Se-Te-Ga thin film at $700 \mathrm{~nm}$ at RT

\begin{tabular}{|l|l|l|l|l|l|l|l|l|}
\hline $\mathbf{X}$ & $\mathrm{E}_{\mathrm{g}}(\mathrm{eV})$ & $\alpha\left(\mathrm{Cm}^{-1}\right)\left(\mathbf{1 0}^{4}\right)$ & $\mathbf{N}$ & $\mathrm{k}\left(\mathbf{1 0}^{-3}\right)$ & $\varepsilon_{r}^{\prime}$ & $\varepsilon_{r}^{\prime \prime}$ & $\mathbf{R} \%$ & $\mathrm{~T} \%$ \\
\hline 0 & 1.51 & 0.70 & 2.01 & 0.39 & 4.07 & 0.002 & 15.63 & 65.62 \\
\hline 0.5 & 1.25 & 0.38 & 2.57 & 0.21 & 6.63 & 0.001 & 29.16 & 70.62 \\
\hline 5 & 1.33 & 1.16 & 5.27 & 0.65 & 27.86 & 0.006 & 75.62 & 58.33 \\
\hline 10 & 1.27 & 1.16 & 2.66 & 0.65 & 7.08 & 0.003 & 31.25 & 64.16 \\
\hline
\end{tabular}


International Journal of Trend in Scientific Research and Development (IJTSRD) ISSN: 2456-6470

Table-3: Variation of $(\alpha h v)^{1 / 2}$ with photon energy in a Se-Te-Ga thin films at Room Temperature.

\begin{tabular}{|c|c|c|c|c|c|}
\hline \multirow[t]{2}{*}{ S. No. } & \multirow{2}{*}{$\begin{array}{l}\text { Photon } \\
\text { Energy E } \\
(\mathrm{eV})\end{array}$} & \multicolumn{4}{|c|}{ Absorption coefficient $(\alpha)$ in $\mathrm{Cm}^{4}$} \\
\hline & & $\mathbf{S e}_{75} \mathbf{I n}_{25} \mathbf{P b}_{0}$ & $\mathrm{Se}_{75} \mathbf{I n}_{21} \mathbf{P b}_{4}$ & $\mathrm{Se}_{75} \mathrm{In}_{19} \mathrm{~Pb}_{6}$ & $\mathrm{Se}_{75} \mathrm{In}_{15} \mathrm{~Pb}_{10}$ \\
\hline 1. & 1.377 & 146.338 & 103.477 & $\mathrm{~N} / \mathrm{A}$ & 73.169 \\
\hline 2. & 1.441 & 150.581 & 106.477 & 75.290 & 75.290 \\
\hline 3. & 1.511 & 147.250 & 98.167 & 85.015 & 85.015 \\
\hline 4. & 1.588 & 124.172 & 87.803 & 101.386 & 113.353 \\
\hline 5. & 1.674 & 111.310 & 82.966 & 143.701 & 143.701 \\
\hline 6. & 1.770 & 207.351 & 108.906 & 184.659 & 210.896 \\
\hline 7. & 1.877 & 283.382 & 179.227 & 237.095 & 283.382 \\
\hline 8. & 1.998 & 374.392 & 258.032 & 334.867 & 355.180 \\
\hline 9. & 2.136 & 443.382 & 322.608 & 427.898 & 416.485 \\
\hline 10. & 2.294 & 527.629 & 392.666 & 527.629 & 527.629 \\
\hline 11. & 2.478 & 580.761 & 478.404 & 649.311 & 620.860 \\
\hline 12. & 2.693 & 631.849 & 560.250 & 760.395 & 694.142 \\
\hline 13. & 2.950 & 948.379 & 948.379 & 1029.579 & 1029.579 \\
\hline 14. & 3.261 & -8 & -000000 & -10 & - \\
\hline
\end{tabular}

The value of $\mathrm{Eg}$ decreases from 1.33 to 1.27 with increasing Ga concentration in $\mathrm{Se}_{70-\mathrm{x}} \mathrm{Te}_{30} \mathrm{Ga}_{\mathrm{x}}$ sample, since the optical absorption depends on the short range order in the amorphous state and defects associated with it. The decrease in the optical band gap in the present system may be due to reduction of the amount of disorder in the system and increase in the density of defect state which is attributed to the shift in Fermi level whose position is determined by the distribution of electrons over the localized states. The values of the variation of $(\alpha h v)^{1 / 2}$ with photon energy (hv) for $\mathrm{Se}_{70-\mathrm{x}} \mathrm{Te}_{30} \mathrm{Ga}_{\mathrm{x}}$ films are given in the table 3.

The variation of reflectance $(\mathrm{R})$ in percentage for the present system of Se-Te-Ga is shown in table 4. The table shows that the reflectance $(R)$ increases with the increase in wavelength. Similarly, the transmittance $(T)$ has also been shown for Se-Te-Ga in table 3. It is evident from the table that the percentage in the transmission increases with respect to wavelength. It is clear from the table that the value of the transmission starts decreasing after about $600 \mathrm{~nm}$.

Table 4: Variation of reflection $(R)$ in \% with wave length in $\mathrm{Se}_{70-\mathrm{x}} \mathrm{Te}_{30} \mathrm{Ga}_{\mathrm{x}}$ thin films at room temperature.

\begin{tabular}{|c|c|c|c|c|c|}
\hline \multirow[t]{2}{*}{ S. No. } & \multirow{2}{*}{$\begin{array}{l}\text { Wave } \\
\text { length in } \\
\mathrm{nm}\end{array}$} & \multicolumn{4}{|c|}{ Reflection (R) in \% } \\
\hline & & Se-Te-Ga & $\mathrm{Se}-\mathrm{Te}-\mathrm{Ga}$ & Se-Te-Ga & Se-Te-Ga \\
\hline 1. & 900 & 88.500 & 62.500 & 31.250 & 28.125 \\
\hline 2. & 800 & 71.833 & 54.583 & 60.417 & 13.750 \\
\hline 3. & 700 & 15.625 & 29.167 & 75.625 & 31.250 \\
\hline 4. & 600 & 46.875 & 14.583 & 30.208 & 41.667 \\
\hline 5. & 500 & 31.667 & 32.500 & 41.667 & 28.125 \\
\hline 6. & 400 & 30.208 & 31.250 & 36.458 & 31.667 \\
\hline 7. & 300 & 28.333 & 22.917 & 29.167 & 22.917 \\
\hline
\end{tabular}


International Journal of Trend in Scientific Research and Development (IJTSRD) ISSN: 2456-6470

Table-5: Variation of Transmission $(T)$ in \% with wave length in a Se-Te-Ga thin films at Room Temperature.

\begin{tabular}{|c|c|c|c|c|c|}
\hline \multirow[t]{2}{*}{ S. No. } & \multirow{2}{*}{$\begin{array}{l}\text { Wave } \\
\text { length in } \\
\mathrm{nm}\end{array}$} & \multicolumn{3}{|c|}{ Transmission (T) in \% } & \multirow[b]{2}{*}{$\mathrm{Se}-\mathrm{Te}-\mathrm{Ga}$} \\
\hline & & Se-Te-Ga & Se-Te-Ga & Se-Te-Ga & \\
\hline 1. & 900 & 40.000 & 56.250 & 75.000 & 82.500 \\
\hline 2. & 800 & 44.792 & 61.458 & 78.125 & 85.938 \\
\hline 3. & 700 & 65.625 & 70.625 & 58.333 & 64.167 \\
\hline 4. & 600 & 14.583 & 48.958 & 19.792 & 21.771 \\
\hline 5. & 500 & 2.083 & 15.625 & 3.125 & 3.438 \\
\hline 6. & 400 & - & 3.125 & 0.208 & 0.229 \\
\hline 7. & 300 & - & 0.208 & - & - \\
\hline
\end{tabular}

The refractive index (n) and extinction coefficient (k) have been calculated by using the theory of reflectivity of light for the above sample discussed. According to this theory, the reflectance of light from a this film can be expressed in terms of fresnel's coefficient. The reflectivity [14-15] on a interface can be given by-R=[(n-1) $\left.)^{2}+k^{2}\right] /\left[(n+1)^{2}+k^{2}\right.$ and $\alpha=4 \pi K /$ $\lambda$

The optical investigations shows that the optical band gap increases upto $4 \%$ of $\mathrm{Ga}$ concentration in Se-Te$\mathrm{Ga}$, with further increase of $\mathrm{Ga}$ content the optical band gap decreases in the present system.

\section{CONCLUSION}

From the reflectance and transmittance studies of the film of Se-Te-Ga, it may be concluded that the refractive index (n) decreases, while the value of the extinction coefficient $\mathrm{k}$ increases with photon energy. The increase in the optical band gap with increasing Ga content may be due to the increase in the grain size, the reduction in the disorder and decrease in the density of defect states. The value of optical band gap (Eg) decreases at higher $\mathrm{Ga}$ concentration. The decrease in the optical band gap in the present system may be due to reduction in the amount of disorder in the system and increase in the density of defect states.

\section{REFERENCES}

1. M.C. Flemings, B. Ilschner, E.J. Kramer, S. Mahajan, K.H. Jurgen Buschow and R.W. Cahn, Encyclopedia of Materials: Science and Technology, Elsevier Science Ltd (2001).

2. 2. Vezzoli, G. C., Walsh, P. J., Doremus, L. W., J. Non-Cryst. Solids, Vol. 18, p. 333(1975).
3. 3. Ovshinsky, S.R., Jpn. J. Appl. Phys., Vol. 43, p. 4695 (2004).

4. Adler, D. et al., J. Appl. Phys., Vol. 51, p. 3289(1980)

5. T. Schweitzer, F. Goutaland, E. Martins, D.W.Hewak and W.S. Brocklesby, Journal of Optical Society of America B (optical physics), 18(10) (2001) 1436.

6. N.Dixit and R.Vijaya, SPIE-The International society for Optical Engineering, 4417 (2001) 477.

7. Ogusk, J.Yamasaki, S.Maeda, M. Kitao and M. Minata, Optics Letters, 29(3) (2004) 265.

8. J.M.Herbold, F.O.Leday, F.W.Wise, S.S.Sanghera, I.D.Agarwal and B.G.Aitken, SPIEThe International society for Optical Engineering, 5601 (2003) 143.

9. M. Abkowitz, G.M.T.Foley, J.M Morkovics and A.C. Palumbo, AIP Conference Proceedings, 120 (1984) 117.

10. N.F. Mott and E.A. Davis, Electronic Process in Non-Crystalline Materials (Clarendon, Oxford, 1979) 428.

11. S. Hsaegawa, S. Yazaki and Slinuzuol, Solid State Commun., 26 (1978) 4070.

12. R.A. Smith, Philos. Mag. 2 (1953) 81.

13. F. Urbach, Physics Rev., 92 (1953) 1324.

14. L.S. Miller, A.J. Walder, P. Lensell and A. Blundell, Thin Solid Films, 165 (1985) 11.

15. J.P. Borgogro, B. Lazarides and E. Pelletier, Appl. Optics, 21 (1982) 4020. 